Original Research Paper

\title{
Detecting Malaysian Housing Bubbles
}

\author{
${ }^{1}$ Yip Chee Yin, ${ }^{2}$ Wong Woei Chyuan and ${ }^{1}$ Woo Kok Hoong \\ ${ }^{I}$ Faculty Business and Finance (FBF), Universiti Tunku Abdul Rahman, Kampar, Perak, Malaysia \\ ${ }^{2}$ School of Economics, Banking and Finance, Universiti Utara Malaysia, Sintok, Kedah, Malaysia
}

Article history

Received: 24-11-2015

Revised: 28-02-2016

Accepted: 16-03-2016

Corresponding Author:

Woo Kok Hoong

Faculty Business and Finance

(FBF), Universiti Tunku Abdul

Rahman, Kampar, Perak,

Malaysia

Email:khwoo@utar.edu.my

\begin{abstract}
This paper examines whether Malaysia is facing an impending housing bubble by using a graphical analysis, logical deduction and two statistical tests. Our research results are robust and supported by a three prone approach: Logical deduction working on the historical price trend based on most recent research findings on bubble; testing the stability of the price cycle and a statistical test modified and formulated in accordance with the Malaysian context to analyze the price trend in the local property market. We show that housing bubble burst is not imminent as yet in Malaysia which is in agreement with Bank Negara Malaysia Report. However, our findings reveal that Malaysia has been experiencing a continuous and increasingly steeper upward movement of house prices without breaks since mid-2009. Exuberant expectation of investment profit seems to be building up continuously, an indication of a strong likelihood of a housing bubble building up. Our findings call for the attention of the government to this development and to take necessary intervention measures.
\end{abstract}

Keywords: House Prices, Boom, Burst, Bubble

\section{Introduction}

House price monitoring has become one of the most popular pastimes in Malaysia. By 2012, more than half of the households in Malaysia owned their own homes while the rest rented their homes. Many of those living in rented properties are the younger working population, keen to have a property of their own. With property prices continuously moving up sharply particularly during the past decade, it is little wonder that these owners in waiting are getting really concerned with housing affordability. Vis-à-vis salary and house prices are not moving in tandem, with the latter far outpacing the former. Demand for houses has been growing due principally to demographical factors, good economic performance and further fueled by the relatively easy availability of financing. Investment in houses brings in lucrative return with rising prices, attracting many into buying properties instead of investing into other stocks. The genuine home-buyers are therefore being posed with the problem of housing affordability, especially those in the urban areas and high development locations, in cities like Kuala Lumpur and George Town. Between 2001 and 2004, house prices in Malaysia increase by an average of $7.3 \%$ per year or $29.2 \%$ over the course of 4 years. Over the following 4 years that is between 2005 and 2008 house prices in Malaysia increase by an average of $6.1 \%$ per year or an accumulated $24.2 \%$. By contrast, from 2009-2012, national real house prices grew by $9.4 \%$ per year or $37.6 \%$ over the 4 years period. This is more than $30 \%$ increase in the annual rate of appreciation when compared with the previous 12 years (2001-2012). This increase of 7.3, 6.1 and $9.4 \%$ are rather steep in comparison with the United States market over the ten-year period from 1995-2004, when national real house prices grew at an annual average of only 3.6 percent (Himmelberg et al., 2005). The house price trend seen in the Malaysian market over the past 15 years is a worrying phenomenon because it is a vital sign of a protracted booming market, the building up of a housing bubble and history shows that a collapse or burst will very likely follow. A bursting housing bubble poses a very significant risk to the national economy. The collapse of the housing bubble will cause enormous economic and social damage, adversely impacting the banking system, household consumption and the real economy of the nation causing untold hardship to the citizens. The disastrous and damaging effect of the bursting of a bubble is well documented in history, example in the United States, the bursting of the housing 
bubble was the principle cause of the 2007-2009 recession. Looking at the long running expansion of house prices in Malaysia, is there a bubble in the property market? If there is, when is the burst of the bubble coming? Many researchers have attempted to answer this question in the developed economies, but each has a different view. In a joint critique study on a research report of the U.S. housing market, Mayer and Shiller (2006), both discussant authors give differing views; while Robert J Shiller is outspoken about the possibility of a housing bubble in US, co-author Christopher Mayer, does not believe that there is a housing bubble in most markets in the US though housing prices are high. Capozza et al. (2002) employs mean reversion regression to show that the price cycle in US market is still stable while Glindro et al. (2011) conducted a panel data analysis of nine Asia countries and by using modified mean reversion regression, they showed that no sign of bubble is observed. In Malaysia so far as we know, there is only one formidable research done by Hussain et al. (2012) who argued for the presence of housing bubble in five districts in Klang Valley, i.e., Ampang, Batu, Kuala Lumpur, Petaling and Setapak during 2005 to 2010. Bubble was measured as the difference between house price and the intrinsic value. However the computation of intrinsic value and definition of bubble is not clearly defined in Hussain et al. (2012) study. Importantly, the authors also did not highlight the magnitude of bubble and verified its existence in the study. We attempt to bridge this gap in the literature by providing two pieces of new evidence and conduct a more scientific and rigorous ways to compute property's intrinsic value using predicted value derived from house price regression model. Thus as a whole, it can be said that there is no consensus with regard to the structure of a housing bubble.

In view of the uncertain nature of detecting housing bubble, this paper offers an alternative approach to investigate whether bubble exists in the Malaysian housing market. We use a graphical analysis coupled with qualitative analysis, utilizing the views and ideas as proposed by well known economists, Christopher Mayer and Quigley (2003) and Case and Shiller (2003). We define the threshold value of house prices for the formation of bubble using the results from this graphical analysis which is primarily based on Mayer (2011) and Glindro et al. (2011). Next, we construct a statistical model specially for testing the continuous upward trend of prices and utilize the mean reversion regression model (proposed by Capozza et al. (2002)) to test for the stability of the house price movement.

Our results show that other than cities like Kuala Lumpur and George Town, Malaysia as a whole, is not facing any impending bubble in the immediate future. However, by providing two pieces of new evidence and through two statistical testing, it is found that Malaysia is facing immense upward surge in house prices especially after the year 2009. Nevertheless, the price cycle is still stable.

The rest of the paper is organized as follows: Section 2 reviews selected contentious housing bubble literature. Section 3 describes the empirical methodologies. Section 4 presents the empirical findings and section 5 concludes this paper.

\section{Literature Reviews}

To-date, there is no consensus on the definition of housing bubble. For example, it is recognized that many countries in the OECD have had a similar trajectory in housing prices as the US had during the last 15-20 years. However, only the supposedly infamous bubble in the US housing market has been given considerable focus. The reason could be that some economists have found that the rampant growth in international housing prices is rational and supported by fundamentals of supply and demand (Himmelberg et al., 2005; OECD, 2005), while others have described these price rises merely as booms and were careful not to define them as bubbles (Agnello and Schuknecht, 2011; Gallin, 2008). Additionally influential housing economists suggested differing views about the existence of housing bubble in the United States (Gerardi et al., 2010). In view of this unsettled issue about the existence of housing bubble, we base our study on the following definition by Mayer (2011) and modified to reflect the Malaysian context.

\section{Definition by Mayer (2011)}

Housing bubbles represent extreme movements of house prices rising rapidly about $20 \%, 30 \%$, or even $40 \%$ per year for two or three years and then falling just as rapidly in the following three years. This type of housing bubble happened in Las Vegas, Phoenix and Miami in this decade and in Vancouver, Canada, in the late 1980s and Japan in the mid-1980s (Mayer, 2011).

However, since this study is on possible bubbles occurring in the Malaysian housing market, we redefine the above definition to suit the Malaysian economic scenario.

\section{Redefinition}

Housing bubbles represent extreme movements of house prices rising rapidly about $20 \%$ (Glindro et al., 2011) per year for two or three consecutive years and then falling just as rapidly in the following two or three years. However, we cannot set $20 \%$ as our threshold value for raising the alarm as intervention policies and measures need time to be implemented and take effect. Thus we choose the mean value that is $10 \%$ as the threshold value. 


\section{Empirical Methodologies}

\section{Fundamental House Prices}

Most bubble models need fundamental house prices for computation. Our two statistical models too require fundamental house prices for calculation. Fundamental house prices are the fitted house prices as a result of regressing actual house prices on housing determinants like mortgage rate, mortgage credit to GDP, GDP, interest rate and so on. The difference between actual and fundamental prices is defined as overvaluation of prices which can be due to normal price adjustment or speculative activity. In this study, we classify overvaluation of prices as the bubble component as illustrated by Equation 1:

$$
P_{t}=f_{t}+B_{t}
$$

where, $P_{t}, f_{t}, B_{t}$ respectively represents house prices, fundamental house prices and bubble component. We further assume that bubble component consists of normal adjustment of prices and prices due to speculation.

Fundamental house prices are the long run average house prices which essentially means long run equilibrium fitted house prices. To compute this long run equilibrium house prices, we follow a three step approach. First, we identify the housing determinants that have significant predictive information about house prices. From literature review, we compiled a list of the determinants from which we select by merit of significance base on conventional wisdom and stepwise regression. The selected significant determinants for this study are GDP, Mortgage Rate (MTR), mortgage credit to GDP ratio (MGD), exchange rate (Japanese Yen/Ringgit) (EXJ) and exchange rate (Hong Kong Dollar/Ringgit) $(\mathrm{EXH})$. Our house prices are in fact house price indexes (HPI) which has the advantage of compensating the difficulty of observing rents for the houses (Mayer and Shiller, 2006).

\section{Cointegrating Regression}

Secondly, we test each determinants to determine whether they are integrated series of order 1 that is $I(1)$. If all the series are $I(1)$ we can conduct cointegrating (long run) regression using both Fully Modified Ordinary Least Square (FMOLS) and Canonical Cointegrating Regression (CCR) estimators. The fitted values from the regression are our fundamental house prices.

\section{Computation of Bubble Component}

Thirdly, we compute the bubble component values (B) by subtracting the fitted house prices from the actual house prices. It is given by Equation 2 in term of percentage:
$B_{p t}=\ln P_{t}-\ln \hat{P}_{t}$

The criterion for likely bubble burst is given by Equation 3:

$B_{p t}>10 \%$

\section{Housing Bubble Investigation Methodologies}

Any housing bubble should consist of a price booming period and then burst which is characterized by a rapid fall in prices for certain length of time. Thus the first step we should do is to show that there is a price booming for certain period of time. This we can do by four different approaches: One, fixing the threshold for booming price surge; two, analyzing the uptrend graph of prices using common psychology; third, testing the stability of the price movement; and four, testing the continuous uptrend price behavior for any sample. These four different approaches are to ensure that we will obtain robust results. The followings are the four types of methodology.

\section{Graphical Analysis}

We analyze price behavior from line graphs by using common logical deduction and incremental analysis. In addition, we also analyze house price-income graph. Besides using normal line graph, we also use \% increment line graph for the analysis. Next by using historical data trend, we define the threshold value for the formation of bubble.

\section{Price Stability Model (PSM)}

PSM is a model for testing the stability of the price cycle. We use mean reversion regression, a short run regression which we use mainly for confirmatory testing of the existence of a housing bubble by showing that the price cycle is not stable and if the price cycle is stable, there is no housing bubble. Mean reversion regression is popularized by Capozza et al. (2002) who propose that house price changes in the short run are governed by reversion to fundamental values and also by serial correlation. Put it differently, deviation from the fundamental house prices are mainly due to economic shocks and that this produces the short-term dynamics of house prices. Thus the formula for this means reversion process is given by Equation 4:

$\Delta p_{t}=\alpha \Delta p_{t-1}+\beta\left(p_{t-1}^{*}-p_{t-1}\right)+\gamma \Delta p_{t}^{*}$

where, $p_{t}$ is $\log$ of (observed) real house prices and $\Delta$ is the difference operator. $p_{t}^{*}$ is the long run house price fundamentals which is obtained by FMOLS cointegrated regression analysis. In efficient housing markets, prices 
will adjust instantaneously so as to maintain $\gamma=1$ and $\alpha=0$. On the other hand, since housing is a slowclearing durable asset, it is reasonable to expect that the current price changes are partly due to previous changes in own price levels, by the deviation from the fundamental value and partly by contemporaneous adjustment to changes in fundamentals.

If $\alpha<1$ and $\beta>0$, the housing cycles are stable, meaning that there is no danger of housing bubble and that price increase is due to fundamental adjustment of prices. The explanation for this condition is as follows. When $\alpha<1$, we expect that the data series is stationary, thus the price cycle is stable. Moreover when $\beta>0$, the fundamental house price is higher than the current price, meaning there is no overvaluation of house price. This confirms that the house price cycle is stable. However if $\alpha \geq 1$ it means that the data series is nonstationary, producing the housing cycles which are explosive. This is confirmed by the condition $\beta \leq 0$, meaning that current house prices are higher than the fundamental prices producing housing cycles which are not stable. Housing bubbles are likely to form.

\section{Price Booming Model (PBM)}

PBM model is used to test whether the price is always in the positive territory or in another words, possible booming. However, we define booming as when the overvaluation of prices is more than $10 \%$. So when it is not more than $10 \%$, it is not a booming phenomenon but normal price increment. Results obtained from analyzing any one sample may not be true for other samples. To ensure that it is true in general, we conduct a simple statistical test. The hypothesis is that if the rising of prices is continuous for a lengthy period, then the investors are likely to develop some herd instincts which make them believe that they will always make profit. This herd instinct would result in exuberant expectation of profit, which is the main reason for boom and subsequently burst of the property bubble. Thus we need to show statistically that there is a continuous unbroken uptrend of price. One of the ways is to examine the house price graph. If the house price graph shows a continuously increasing trend, this will boast speculators' confidence that prices will increase in the immediate future. Put it differently, "exuberant herd instinct" is building up in investors' mind. Such sentiments can turn into an irrational exuberance that will bring about the bursting of the housing bubble if no intervention measures are imposed to check the development of the volatile situation. PBM is to test whether the results from sample specific method are statistically significant or if the result is truly indicative of a consistent difference "in population". This idea of statistical testing follows along the same line as Diebold and Mariano (DM) comparing predictive accuracy test
(1995). This sign test is denoted by $Y$ hereafter. We let our overvaluation series be $\mathrm{P}$ where $P=\left\{d_{t}\right\}_{t=1}^{t=40}$.

We generate 3 series for $n=1,2$ and 3 which are the 1 st, 2nd and 3rd difference of $P$. Thus, the difference between recent and 2 nd quarter overvaluation, recent and 3rd quarter overvaluation and recent and 4th quarter overvaluation are given by Equation 5:

$O_{n j}=\left\{d_{t}\right\}_{t=1}^{t=40-n}-\left\{d_{t}\right\}_{t=1+n}^{t=40} \quad$ for $\mathrm{n}=1$ to 3

For $n=1,2$ and 3, the 1st, 2nd and 3rd difference series of $\mathrm{P}$ are given by $\left\{O_{1 j}\right\}_{j=1}^{j=39},\left\{O_{2 j}\right\}_{j=1}^{j=38}$ and $\left\{O_{3 j}\right\}_{j=1}^{j=37}$. By adding all the terms in the 3 series together, we have $T=39+38+37=114$ Equation 6 to 8 :

$$
\begin{aligned}
& P_{k t}=\left\{O_{1 j}\right\}_{j=1}^{j=39}+\left\{O_{2 j}\right\}_{j=1}^{j=38}+\left\{O_{3 j}\right\}_{j=1}^{j=37} \\
& P_{k t}=\left\{P_{k t}\right\}_{k=1}^{k=114}
\end{aligned}
$$

$P_{k t}^{+}=$all positive $P_{k t}$

We assume that $P_{k t}^{+}$follows the binomial distribution with parameters $\mathrm{T}$ and $1 / 2$. We test the following null hypothesis against the alternative hypothesis. The null hypothesis is that the overvalued house prices at the present period are the same as previous one or two periods before. The alternative hypothesis is that the overvalued house price at the present period is always greater than one or two periods before. Thus we have the following:

$H_{0}: P_{k t}^{+}=0$
$H_{a}: P_{k t}^{+}>0$

The criterion is that if we reject the null hypothesis, it means that the overvalued house price is always in the increasing trend when compared to one or two previous periods. This implies that house prices are always on the upward trend, indicating the onset of housing bubbles. The test statistic is therefore given as:

$S_{1}=\sum_{k=1}^{T} I\left(P_{k t}\right)$

where, Equation 11:

$$
\begin{aligned}
I\left(P_{k t}\right)=1 & \text { if } P_{k t}>0 \\
=0 & \text { otherwise }
\end{aligned}
$$


Since $T=39$ which is reasonably large, we can consider the data as asymptotical normal and use studentized $t$ distribution for the test statistic $Y$. Thus we have the test statistic given as:

$Y=\frac{S_{1}-0.5 T}{\sqrt{0.25 T}} \sim N(0,1)$

To test the consistency of the result obtained by Equation 10, we also conduct the Wilcoxon's signedrank test:

$$
S_{2}=\sum_{k=1}^{T} I\left(P_{k t}\right) \operatorname{rank}\left(\left|P_{k t}\right|\right)
$$

The studentized version is asymptotically standard normal Equation 14:

$$
X=\frac{S_{2}-\frac{T(T+1)}{4}}{\sqrt{\frac{T(T+1)(2 t+1)}{24}}} \sim N(0,1)
$$

\section{Empirical Findings}

\section{Graphical Analysis}

Figure 1 shows house prices are on a continuous upward trend for the period from 2001 to 2012. The rise is increasingly steeper from 2009 to 2012. This continuous uptrend of prices suggests investors' confidence of sure making profit, starts to build up slowly from 2001 to 2008 but escalated upwards from 2009 to 2012. This behavior corresponds with Shiller (2006) concept of bubble whereby he describes bubble happens when exuberant herd instinct of tomorrow making good profit, starts to develop. Looking from the percentage perspective as in Fig. 2, from 2001 to 2008, prices fluctuate about $1.5 \%$ from positive to negative, about an average annual rate of about $2.5 \%$. However, from 2009 to 2012, annual prices increase from about 2 to $13 \%$ in a time span of 4 years and there is no negative rate of increase at all. The first piece of evidence is shown in Fig. 3 which shows the variation of house prices and income. Between 2001 and 2008, income moves parallel with house prices which is the norm since with more income, more people will buy houses and thus pushing up house prices. However, despite the drastic drop in income for the period 2008 to 2009 , house prices still rally upward. Subsequently income goes up in 2010 but it drops again in 2011 . Apparently house prices are not sensitive to the fluctuation of income, a possible indication that investors are convinced that house prices will continue to rise and thus very certain of a profitable return for their investments. This is a vital sign for the formation of housing bubble. The second piece of evidence is that the rapid rate of house price growth of $7.3,6.1$ and 9.4\% between 2001-2004, 2005-2008 and 2009-2012 exceed the overall inflation rate of about $3.5 \%$ and growth rate of income which is proxied by GDP is about $6 \%$. This demonstrates the rampant growth of house prices and the building up of investors' confidence in the property market. Such speculative sentiment, if it continues to heighten may contribute to the built-up of the feeling of irrational exuberance among all parties involved in the housing marketproperty investors, developers, the financial sector as well as the government authorities. Irrational exuberance, when the market players are convinced of non-stop rising house prices, is a key contributor to the formation of a housing bubble (Holt, 2009).

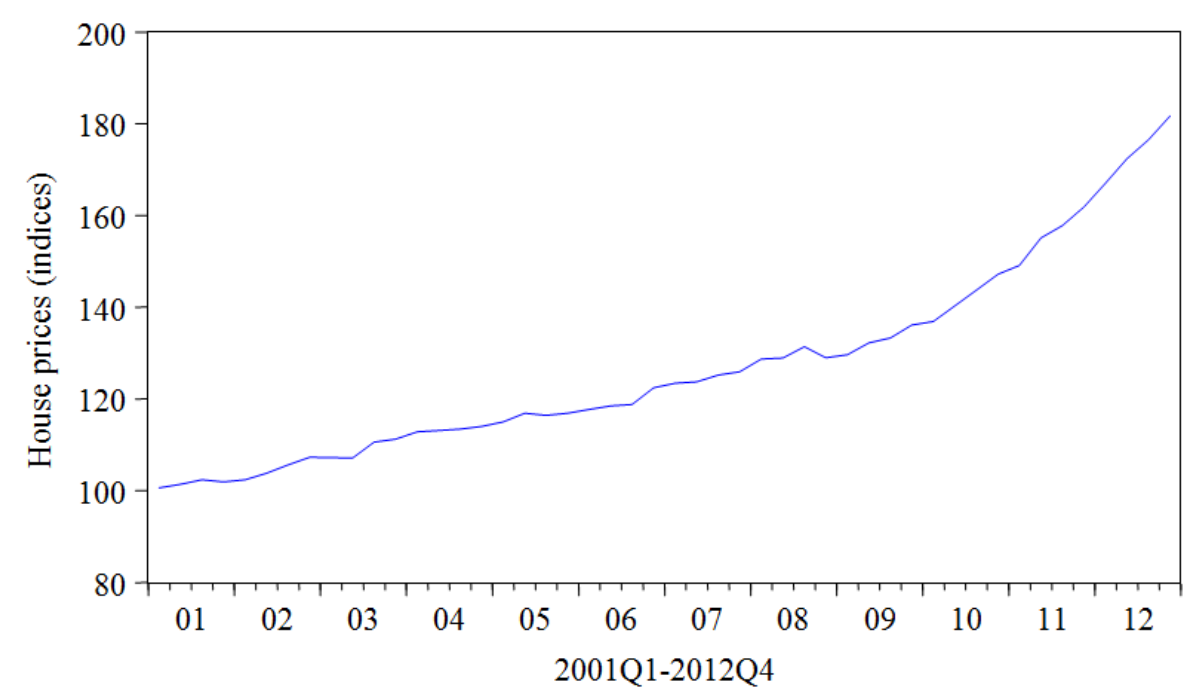

Fig. 1. Uptrend movement of house prices 


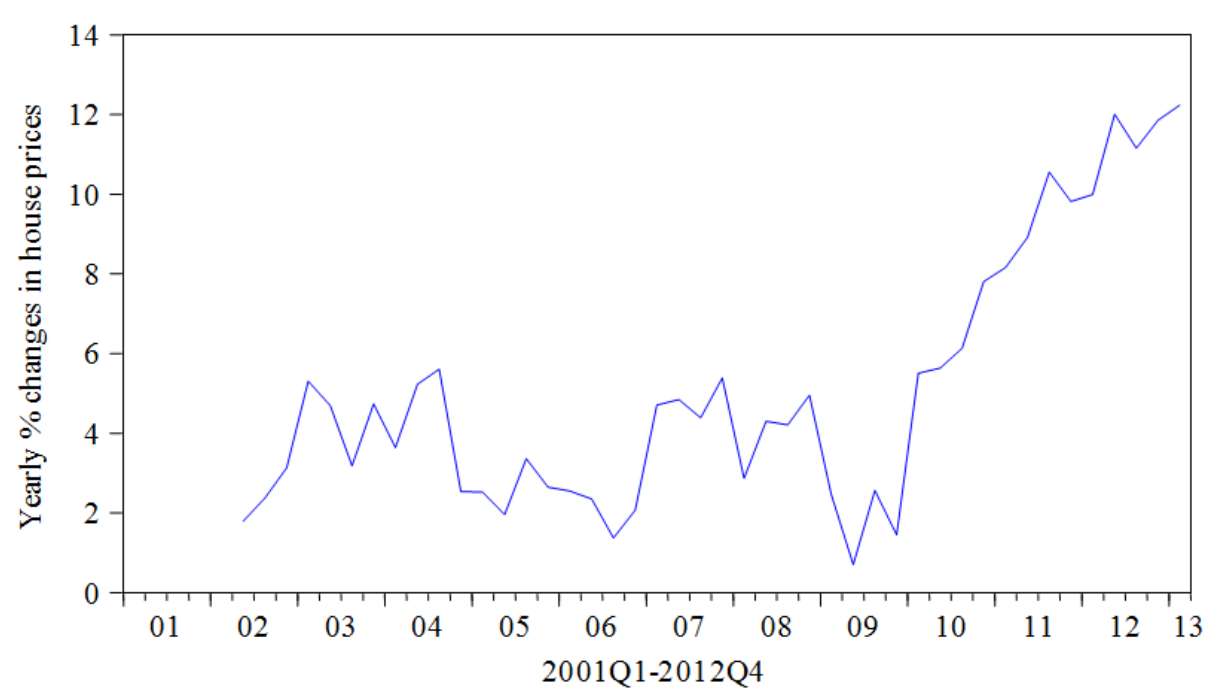

Fig. 2. Annual \% changes house prices

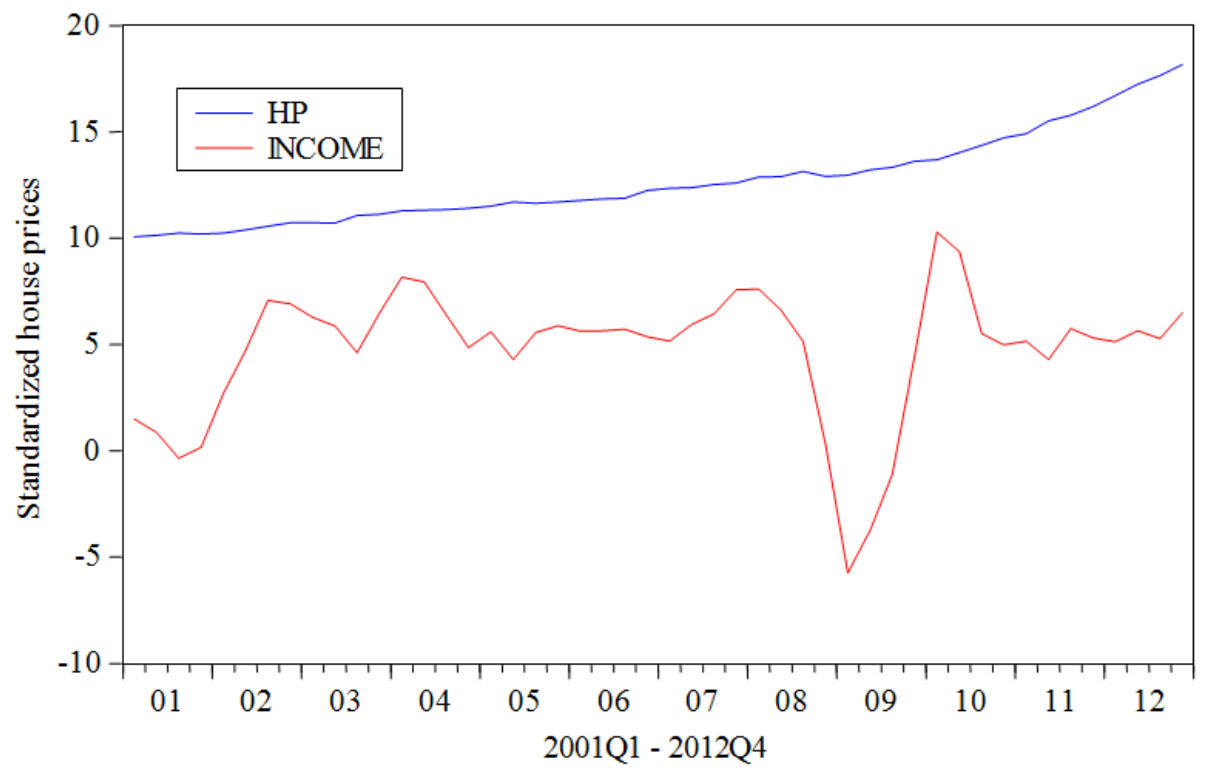

Fig. 3. House prices and income

\section{Are House Prices Booming?}

The most popular method for detecting bubble is to compare the observed house prices with fundamental house prices which are predicted based on the long run relationship between house prices and macroeconomic and financial factors. The main weakness of this method is the difficulty to obtain the correct set of housing determinants to run effective cointegrating regression. To this end, we examine past literature for housing determinants, follow general to specific rule to run regression and then combine the results from two different long run cointegrating regression (see section 3.1).

Prior to performing cointegrating regression, Granger (1969) causality test and Johansen (1994) multivariate approach to cointegration test, it is necessary to confirm whether the dependent variable is $I(1)$ and all the explanatory variables are also $I(1)$ and no $I(0)$ explanatory variable. For this purpose, we conduct ADF and KPSS unit root test. Then we confirm the results using DF-GLS test. Following the confirmation of the initial statistical tests, we perform the Johansen multivariate cointegration test and 
Granger causality analysis. The results show that all the variables, HP, GDP, MTR, EXJ, EXH and MGD are $\mathrm{I}(1)$ and cointegrated, meaning that there is a long run relationship among them. Then we run the VECM model and the end result is that GDP, MTR, MGD, EXJ and EXH each has long run causality with HP, running from each determinant to House Prices (HP). However, the results of Granger causality test suggest that HP to GDP and HP to EXH are unidirectional. It seems that there is no short run causality from GDP, MGD, MTR, EXJ and EXH to HP. This indicates that there is no short run equilibrium among the variables in level. This supports our preference for long run causality analysis. Therefore, we conclude that HP in the real estate sector and its determinants in Malaysia are cointegrated and there is a meaningful long-run relationship between them. Then from the results of cointegrating regression of Table 1 , we compute the fitted values of house prices either by taking the simple average of the two values obtained from FMOLS and CCR respectively or using the best fitted model. The fitted values or the fundamental prices are shown in Equation 15:

$$
\hat{p}_{t}=E\left[p_{t}\right]
$$

where, $\hat{p}_{t}$ represents the fitted house prices and $p_{t}$ is the house price.

\section{Long Run (Cointegrating) Regression Results}

When FMOLS is compared with CCR, both of them produce a set of results which is not in conflict with economic theory and conventional wisdom. However, FMOLS has a better set of adjusted $\mathrm{R}$ square, long run variance and standard error of regression. Hence, we either select the set of results produced by using FMOLS from model 1 to compute the fundamental house prices using Equation 8, or the combined model of M1 and M2 of FMOLS and CCR. Since FMOLS and CCR are different types of models, we cannot combine the models. Thus we use model 1 of FMOLS to compute the fundamental house price. Next, we compute $B_{p t}$ by using Equation 2 and keeping in mind that $B_{p t}$ must be more than $10 \%$ for possible bubble to exist. The results are shown in Table 2 .

The results shown in Table 2 indicates that $B_{p t}$ is always less than $10 \%$. The criterion in Equation 3 is not satisfied and therefore there is no booming yet. However, steep uptrend of prices is obvious from the graphical analysis. We need to test whether this uptrend is sample specific or it can be applied in general. So we use statistical test to gauge whether this uptrend is acceptable or not.

\section{Statistical Uptrend}

We test this uptrend by conducting the PBM model. The results are shown below. The argument in (2) shows that uptrend is currently happening but is it true in general? Is the uptrend sample specific only? To investigate this, we conduct a statistical test to show that this uptrend is true in general. The result of the investigation is as follows: We conduct the $Y$ sign test and $X$ sign test as explained in Equation 9, 12 and 13. For $T=114$, the studentized version of the $Y$ and $X$ sign tests are asymptotically standard normal. For $Y$ test we have the following statistics $\left(d_{t}=p_{t}^{*}-p_{t}, p_{t}^{*}-p_{t+1}, p_{t}^{*}-p_{t+2}\right)$ and thus overvaluation is a left tailed test:

$$
\begin{aligned}
S_{1} & =\sum_{i=1}^{T} I_{+}\left(d_{i}\right)=32 \\
X & =\frac{2469-3335}{358.33}=-2.417<-1.96 \\
Y & =\frac{32-0.5 \times 114}{\sqrt{0.25 \times 114}}=-4.755<-1.96
\end{aligned}
$$

where, -1.96 is the $5 \%$ critical value for rejecting the null hypothesis. Thus we reject the null hypothesis that the present overvaluation is the same as the previous overvaluation. Since the present overvaluation is computed by subtracting the price of the previous one quarter, previous two quarters and previous three quarters from the price of the present quarter, there is evidence that the present overvaluation is more robust as the present price is more than the price from first, second and third quarters.

For $X$ test, we have the following statistics too:

$$
S_{2}=\sum_{k=1}^{T} I\left(P_{k t}\right) \operatorname{rank}\left(\left|P_{k t}\right|\right)=2469
$$

Thus we still reject the null hypothesis as the $Y$ test. Thus, this $X$ test confirms the $Y$ test results. Therefore our testing result is consistent. The results of this statistical test indicate that overvaluation of house prices may be small but it is consistent since it is in agreement with the historical trend investigation as in graphical analysis.

\section{Price Cycle Stability}

So we do not have any bubble yet based on our definition. However, prices show trend of starting to spike up. The next question is: Is the price cycle stable or unstable? If unstable, then it is an indication of possible housing bubble formation. We test the stability by using mean reversion regression as described in section 4.2.

The results are shown in Table 3 below. 
Table 1. Cointegrating regression results with house price HP as dependent variable

\begin{tabular}{lll} 
& FMOLS & CCR \\
Model & Model 1 & Model 2 \\
\hline GDP & $0.11(0.01)$ & $0.11(0.02)$ \\
MGD & $18.68(0.00)$ & $18.41(0.00)$ \\
MTR & $-2.02(0.02)$ & $-2.05(0.03)$ \\
EXJ & $4.62(0.00)$ & $4.63(0.00)$ \\
EXH & $-1.35(0.00)$ & $-1.37(0.00)$ \\
Adjusted R & 0.98 & 0.98 \\
long run VAR & 1.24 & 1.24 \\
S.E.regression & 1.35 & 1.36 \\
\hline
\end{tabular}

Note: $\mathrm{VAR}=$ variance S.E. regression $=$ standard error of regression

Table 2. Annual Overvaluation of Prices (OVP) in percent

\begin{tabular}{|c|c|c|c|c|c|c|c|c|c|c|c|c|c|}
\hline Years 2001-2012 & 01 & 02 & 03 & 04 & 05 & 06 & 07 & 08 & 09 & 10 & 11 & 12 & Total \\
\hline $\begin{array}{l}B_{p t}=\text { Annual } \\
\text { OVP in } \%\end{array}$ & 1.1 & 0.8 & 2.0 & 1.5 & 2.3 & 3.8 & 2.2 & 0.4 & 0 & 3.5 & 3.7 & 4.1 & 25.4 \\
\hline
\end{tabular}

Table 3. Short run house price dynamics

\begin{tabular}{lccc}
\hline Variable & Coefficients & t stat & p-value \\
\hline $\mathrm{c}$ & 0.0069 & 3.3748 & 0.0019 \\
$\Delta p_{t-1}$ & -0.3225 & -2.4485 & 0.0197 \\
$p_{t}^{*}-p_{t}$ & 0.0047 & 4.6211 & 0.0001 \\
$\Delta p_{t}^{*}$ & 0.0052 & 4.0224 & 0.0003 \\
Adjusted R & & \\
F(p-value & 0.4516 & & \\
S.E.regression & 0.0000 & & \\
\hline Not:Pesisti & 0.0077 & & \\
\hline
\end{tabular}

Note: Persistence parameter $\alpha=-0.3225$

Mean reversion parameter $\beta=0.0047$

Contemporaneous adjustment parameter $\gamma=0.0052$

Since $\alpha<1$ and $\beta>0$, thus the house price cycle is stable, that is, house price increases are due to fundamentals only (Capozza et al., 2002). In addition, it is found that $(1+\alpha-\beta)^{2}-4 \alpha=1.963>0$. This implies that the transitory path in response to changes in equilibrium house price value suggests a damped fluctuation around the equilibrium level. The property of oscillation is determined by the magnitude of $\alpha+\beta$. Usually, a higher $\alpha$ indicates a higher amplitude of price oscillation while a higher $\beta$ implies a higher frequency of the fluctuation process. As a whole, since the house price is stable, it lends support to the previous testing by using historical data information that the house prices are efficient in the sense that it follows the fundamental path.

\section{Conclusion}

By using graphical analysis and some consideration of psychology, we come to the conclusion that investors' confidence in believing that house prices will continue to rise is building up. This exuberant herd instinct which is the primary cause for the formation of bubbles, may not be true for other samples. However, through a statistical testing technique, it is found that this exuberant expectation that the price will be high tomorrow is true in general within 5\% statistical significance. This is our major contribution in this study. Moreover, using historical data from the formation of bubble in the United States, Japan and Canada and also Malaysia's past boom and burst of housing prices, we define $10 \%$ above the fundamental values as the threshold and above which a bubble exists in the market. By this consideration, our study results show that Malaysia is not facing a housing bubble yet. This fact is further backed up by our price stability test whereby it is found that the price cycle is stable. Moreover, our main finding is in agreement with what have been found out by Bank Negara Malaysia centre bank of Malaysia (2012) Report and IMF Report (2014). The result of this study should serve as a call to the Malaysian authorities to commence vigilant monitoring of the situation as well as to implement appropriate and timely interventions in the property market so as to prevent overheating. However, in this study, we face a number of limitations. One of which is that we are not yet able to estimate the threshold value of exuberant 
expectation, above which the market is considered overheated and a bubble is developing. This could be the focus issue for future research.

\section{Acknowledgement}

A special thank to Universiti Tunku Abdul Rahman, Universiti Utara Malaysia as well IMF policy that promote a wider reach of data and make it available to public.

\section{Author's Contributions}

All authors equally contributed in this work.

\section{Ethics}

This article is original and contains unpublished material. The corresponding author confirms that all of the other authors have read and approved the manuscript and no ethical issues involved.

\section{References}

Agnello, A. and L. Schuknecht, 2011. Booms and busts in housing markets: Determinants and implications. J. Hous. Econom., 20: 171-190. DOI: $10.1016 /$ j.jhe.2011.04.001

BNMR, 2012. Developments in the housing market and implications on financial stability. Financial Stability and Payment Systems Report, Bank Negara Malaysia Report.

Capozza, D.R., P.H. Hendershott, C. Mack and C.J. Mayer, 2002. Determinants of real house price dynamics. National Bureau of Economic Research, Cambridge.

Case, K.E. and R.J. Shiller, 2003. Is therea bubble in the housing market. Brook. Paper Economic Activity, 2: 299-362. DOI: 10.1353/eca.2004.0004

Gallin, J., 2008. The long-run relationship between house prices and rents. Real Estate Econom., 36: 635-658. DOI: 10.1111/j.1540-6229.2008.00225.x

Gerardi, K.S., C.L. Foote and P.S. Willen, 2010. Reasonable people did disagree: Optimism and pessimism about the U.S. housing market before the crash. Federal Reserve Bank of Boston, Public Policy Discussion Paper.
Glindro, E.T., T. Subhanij, J. Szeto and H. Zhu, 2011. Determinants of house prices in nine Asia-pacific economies. Int. J. Central Bank., 7: 163-204.

Granger, C., 1969. Investigating causal relations by econometric models and cross-spectral methods. Econometrica, 37: 472-492. DOI: 10.2307/1912791

Hussain, M.Y., R.A. Rahman, F. Nabilla, M. Husain and N. Lyndon et al., 2012. Housing bubbles assessment 2005-2010: Experiences in Klang Valley, Malaysia. Adv. Natural Applied Sci., 6: 33-41.

Himmelberg, C., C. Mayer and T. Sinai, 2005. Assessing high house prices: Bubbles, fundamentals and misperceptions. J. Econom. Perspectives, 19: 67-92. DOI: $10.1257 / 089533005775196769$

Holt, J., 2009. A summary of the primary causes of the housing bubble and the resulting credit crisis: A non-technical paper. J. Bus. Inquiry, 8: 120-129.

IMFR, 2014. Financial sector assessment program. Malaysia-Housing Market Technical Note, IMF Country Report No. 14/99.

Johansen, S., 1994. The role of the constant and linear terms in cointegration analysis of nonstationary variables. Econometric Rev., 13: 205-229. DOI: 10.1080/07474939408800284

Mayer, C., 2011. Housing bubbles: A survey. Annual Rev. Econom., 3: 559-577.

DOI: 10.1146/Annurev.Economics.012809.103822

Mayer, C. and J.M. Quigley, 2003. Is there a bubble in the housing market? Comments and discussion. Brook. Papers Economic Activity, 2: 343-362

Mayer, C. and R.J. Shiller, 2006. Bubble, bubble, where's the housing bubble. Comments and discussion, Papers Economic Activity.

OECD, 2005. Recent house price developments: The role of fundamentals. OECD Report, Economic Outlook.

Shiller, R.J., 2006. Long-term perspectives on the current boom in home prices. Economists' Voice, 3: 1553-3832. DOI: 10.2202/1553-3832.1145 